\title{
UNILATERAL PROPTOSIS - A DIAGNOSTIC DILEMMA
}

\author{
Ubaid Ullah Yasin, Muhammad Amer Yaqub, Syed Abid Hassan Naqvi, Muhammad Shahid, Asad Habib, Muhammad Awais* \\ Armed Forces Institute of Ophthalmology/National University of Medical Sciences (NUMS) Rawalpindi Pakistan, *Combined Military Hospital Sargodha/ \\ National University of Medical Sciences (NUMS) Pakistan
}

\begin{abstract}
Objective: To study epidemiology, presentation and management of cases with unilateral proptosis presenting at a tertiary care hospital.

Study Design: Case series.

Place and Duration of Study: Armed Forces Institute of Ophthalmology, Rawalpindi Pakistan, from Jan 2016 to Dec 2017.

Methodology: Retrospective analysis of hospital record of patients with unilateral proptosis was carried out. Data was entered and analyzed in SPSS version 22. Chi square test was used for statistical analysis.

Results: Thirty-three cases of unilateral proptosis with a mean age of $41.79 \pm 3.87$ years were included in the study. Pain was the most common association. Proptosis was mild in $42.4 \%$, moderate in $48.5 \%$ and severe in $9.1 \%$ cases. In $61 \%$ cases, diagnosis was made on excisional or incisional biopsy and on the basis of radio imaging in $39 \%$ cases. Most common cause of proptosis found was pleomorphic adenoma (12\%). Patients with axial and non-axial proptosis were $48.5 \%$ and $51.5 \%$ respectively. Fourteen cases $(42.5 \%)$ were managed surgically and 2 cases $(6 \%)$ were observed. Total of 22 cases $(67 \%)$ improved after treatment, 8 cases (24\%) went into remission, $2(6 \%)$ deteriorated, and $1(3 \%)$ died in the study period.

Conclusion: Unilateral proptosis is a diagnostic challenge. Pertinent history taking and detail examination is the key, but associated signs or symptoms not always point towards correct diagnosis. Tissue biopsy provides a conclusive diagnosis especially where radio imaging is doubtful.
\end{abstract}

Keywords: Exophthalmos, Hertel, Proptosis, Pleomorphic adenoma, Thyroid eye disease.

How to Cite This Article: Yasin UU, Yaqub MA, Naqui SAH, Shahid M, Habib A, Awais M. Unilateral Proptosis - A Diagnostic Dilemma. Pak Armed Forces Med J 2021; 71(5): 1755-1758. ～doi: https://doi.org/10.51253/pafmj.v71i5.3593

This is an Open Access article distributed under the terms of the Creative Commons Attribution License (https://creativecommons.org/licenses/by-nc/4.0/), which permits unrestricted use, distribution, and reproduction in any medium, provided the original work is properly cited.

\section{INTRODUCTION}

The term proptosis and exophthalmos are generally used interchangeably. Some authors use term exophthalmos for causes related to endocrine problems and proptosis for others. ${ }^{1}$ Others use the severity of protrusion to differentiate between the two with more severe cases termed exophthalmos. ${ }^{2}$

The absolute cut off value to label proptosis varies in literature $(16 \mathrm{~mm}$ or $18 \mathrm{~mm})$ but the difference of 2 $\mathrm{mm}$ between two eyes is more specific. ${ }^{3}$ Proptosis can also be assessed radiologically with CT or MRI axial scan using the interzygomatic line. ${ }^{4}$ Distance is measured between this line and the anterior (normal $<21$ $\mathrm{mm}$ ) or posterior globe margin (normal $<5 \mathrm{~mm}$ ). ${ }^{5,6}$

There are also different methods to measure proptosis. Various instruments have been designed for clinical measurement of proptosis, ranging from a simple ruler to more precise instruments like hertel, naugle and leudde's exophthalmometers but hertel exophthalmometer which was designed in 1905 is most commonly used. ${ }^{7}$ However, exophthalmometry is affected

Correspondence: Dr Ubaid Ullah Yasin, Classified Eye Specialist, Pakistan Naval Ship, Shifa Hospital, Karachi Pakistan

Received: 05 Dec 2019; revision received: 09 Feb 2020; accepted: 10 Feb 2020 by several factors such as ethnicity, gender and age. ${ }^{8}$ Interobserver variations has been reported in literature ranging between various designs. . $^{910}$

Proptosis can present with painful red eye, chemosis, loss of sight or color vision or restriction of extraocular movements. Other associations include fever, pain, diplopia, epiphora and nasal discharge. Depending upon the age of patient, presentation and laterality of disease, etiology ranges from simple diseases like thyroid ophthalmopathy to more serious infections like mucormycosis, benign or malignant tumors like adenomas, hemangiomas, meningiomas, gliomas and secondary metastasis.

Unilateral proptosis is a diagnostic challenge. The objective of this study was to know about its varying presentations and etiologies. Timely referral to tertiary care center and following standardized operating procedures in assessment helps in early diagnosis and effective treatment.

\section{METHODOLOGY}

It was a case series, conducted at Armed Forces Institute of Ophthalmology, Rawalpindi Pakistan, from January 2016 to December 2017. Thirty three Patients of unilateral proptosis were managed. Detailed eye 
examination was done and variables including demographic data, associated symptoms, physical examination, laboratory studies, radiological workup, direction and laterality, Treatment and follow-up were recorded on a predesigned study proforma

Inclusion Criteria: Patients of unilateral proptosis were included. Proptosis was measured using Hertel's exophthalmometer.

Exlusion Criteria: The cases with bilateral exophthalmos, pseudoproptosis, those with obvious craniofacial anomalies in which proptosis was a feature and recurrent cases managed in the past were excluded from the study.

For this study, proptosis was defined as a reading of $\geq 18 \mathrm{~mm}$ or a difference between both the two eyes of $>2 \mathrm{~mm}$ whichever applicable. Proptosis of $2-4 \mathrm{~mm}$ was considered as mild uptil $6 \mathrm{~mm}$ as moderate and $>6 \mathrm{~mm}$ as severe. Diagnosis was made provisionally based on history, detailed ophthalmic examination and after relevant radiological investigation like computerized tomography, magnetic resonance imaging and ultrasound B-scan whichever indicated. Prior biopsy was also performed in some patients before definitive management. The inflammations were managed medically with systemic antibiotics and steroids while for tumors either benign or malignant, surgical management (orbital explorations, orbitotomies, exenterations) was planned.

Patients were managed in consultation with other specialties like ENT, Radiology, neurosurgery, and oncology and were referred for post op radiotherapy and chemotherapy wherever indicated. Data was grouped into variables and analyzed with SPSS version 22 . Chisquare test was used for statistical analysis. $p$-value of $<0.05$ was considered significant.

\section{RESULTS}

Thirty-three cases of unilateral proptosis were managed during the study period with a mean age of $41.79 \pm 3.87$ years. Seventeen $(51.5 \%)$ patients were male and $16(48.5 \%)$ were female. Out of them 19 $(48.5 \%)$ patients presented with axial and 20 (51.5\%) patients presented with non-axial proptosis. The duration of proptosis is shown in the Table-I.

A total of 29 cases presented with gradual onset of proptosis, including 19 cases $(57.6 \%)$ with gradual painless and 10 cases (30\%) with gradual painful. Only 4 cases $(12 \%)$ had sudden painful unilateral proptosis (acute orbit). There was no significant difference in the frequency distribution of these case presentations and the accuracy of proptosis diagnosis $(p=0.63)$.

Only 2 cases $(6 \%)$ had no associated signs or symptoms while the most common presentation was pain (headache or ocular pain) in 14 cases $(42.5 \%)$. Rest of the cases presented with variable associations like diplopia in $4(12 \%)$, ptosis in $6(18.2 \%)$, reduced vision in 5 $(15.2 \%)$ ocular pain and redness in $2(6 \%)$ each (TableII).

Table-I: Duration of proptosis.

\begin{tabular}{|c|c|}
\hline Diagnosis & Frequency (n) \\
\hline Malignant Tumors & 7 \\
\hline Lymphoma & 3 \\
\hline Malignant fibrous tumor & 1 \\
\hline Sebaceous gland carcinoma & 1 \\
\hline Adenoidcystic carcinoma & 1 \\
\hline Rhabdomyosarcoma & 1 \\
\hline Benign Tumors & 12 \\
\hline Pleomorphic adenoma & 4 \\
\hline Meningioma & 2 \\
\hline Capillary hemangioma & 2 \\
\hline Cavernous hemangioma & 2 \\
\hline Deep dermoid & 1 \\
\hline Pilocytic astrocytoma & 1 \\
\hline Inflammation & 3 \\
\hline IgG4 Orbitopathy & 1 \\
\hline Thyroid eye disease & 1 \\
\hline Fibrovascular tissue inflammation & 1 \\
\hline Acute Orbit & 4 \\
\hline Panophthalmitis & 1 \\
\hline Orbital Haemorrhage & 1 \\
\hline Choclate Cyst, Lymphangioma & 1 \\
\hline Cavernous Sinus Thrombosis & 1 \\
\hline Miscellaneous & 7 \\
\hline Mucormycosis & 2 \\
\hline Pseudotumor & 1 \\
\hline Metastasis & 1 \\
\hline Frontal Mucocele & 1 \\
\hline Lacrimal adenitis & 1 \\
\hline Carotid cavernous fistula & 1 \\
\hline
\end{tabular}

Table-II: Associated signs and symptoms.

\begin{tabular}{l|c|c}
\hline Association & Frequencey (n) & Percentage (\%) \\
\hline Headache & 12 & $36.4 \%$ \\
\hline Ptosis & 6 & $18.2 \%$ \\
\hline Reduced vision & 5 & $15.2 \%$ \\
\hline Diplopia & 4 & $12 \%$ \\
\hline Ocular pain & 2 & $6 \%$ \\
\hline Red eye & 2 & $6 \%$ \\
\hline No Association & 2 & $6 \%$ \\
\hline
\end{tabular}

A total of 3 cases (9\%) presented with an initial visual acuity of no perception of light, while 16 cases $(48.5 \%)$ had normal vision at presentation. Remaining 14 cases $(42.4 \%$ ) had a variable vision from $6 / 9$ to $6 /$ 60 at presentation. Proptosis was mild in 14 cases 
$(42.4 \%)$, moderate in 16 cases $(48.5 \%)$ and severe in 3 cases $(9.1 \%)$. Extraocular movements were limited to a variable extent in 7 cases (21 \%) while it was full range in remaining $26(79 \%)$.

In all 33 cases radio-imaging was done first to reach a provisional diagnosis. In 17 cases (51.5\%) the diagnosis was confirmed after excision biopsy. Fourteen were surgically managed by orbitotomies or orbital exploration out of which 3 underwent exentration. Following surgery, 5 underwent radiotherapy and chemotherapy. In 3 cases (9\%) incisional biopsy confirmed the diagnosis and these all were managed medically. In remaining 13 cases $(39.4 \%)$ radio imaging helped in making the diagnosis. In tumors, histopathology reports confirmed the final diagnosis. Tissue biopsy was statistically found to be significantly superior to radioimaging in correctness of diagnosis $(p<0.01)$, as illustrated in the Table-III.

Table-III: Diagnostic frequencies of tissue biopsy and radio imaging.

\begin{tabular}{l|c|c|c}
\hline & $\begin{array}{c}\text { Tissue } \\
\text { Biopsy }\end{array}$ & $\begin{array}{c}\text { Radio } \\
\text { Imaging }\end{array}$ & $\begin{array}{c}p \text { - } \\
\text { value }\end{array}$ \\
\cline { 1 - 3 } Correct Diagnosis & $18(90 \%)$ & $13(39.4 \%)$ & \multirow{2}{*}{$<0.01$} \\
$\begin{array}{l}\text { Incorrect/Inconclusive } \\
\text { Diagnosis }\end{array}$ & $2(10 \%)$ & $20(60.6 \%)$ & \\
\hline
\end{tabular}

Table-IV: Etiology of unilateral proptosis, duration of proptosis.

\begin{tabular}{l|c|c}
\hline Duration & Cases & Percentage(\%) \\
\hline$<1$ month & 03 & $9 \%$ \\
\hline 1-6 months & 09 & $27.3 \%$ \\
\hline $6-12$ months & 09 & $27.3 \%$ \\
\hline 1-2 Years & 05 & $15 \%$ \\
\hline$>2$ Years & 07 & $21 \%$ \\
\hline
\end{tabular}

common diagnosis of orbital lymphoma in 3 out of 7 cases $(42.85 \%)$. Remaining 14 patients had variable diagnosis as mentioned (Table-IV). During the study period 22 cases $(67 \%)$ improved with no residual disease, in 8 cases $(24 \%)$ disease went into remission phase, 2 $(6 \%)$ steadily deteriorated, and there was $1(3 \%)$ mortality in the study period.

\section{DISCUSSION}

In case of bilateral protrusion of eyeballs, the provisional list of diagnosis is rather short however, unilateral cases have a long list of etiologies. Bilateral cases may initially present unilaterally. ${ }^{11}$ The patient can present with varying signs and symptoms as mentioned in the literature. ${ }^{6}$ Fever, diplopia, pain, redness, chemosis or associated signs like epiphora, running nose, difficult breathing are few leading ones. ${ }^{12}$ The causes like inflammatory, endocrine and neoplastic all can present initially with a protrusion of eyeball that is, proptosis.13,14 Malignant causes can present with sudden protrusion and loss of visual acuity. Orbital metastasis can have a primary source elsewhere in the body. On account of these variable presentations, signs, symptoms and course of disease that it follows, each case of proptosis is in fact a diagnostic challenge. Timely diagnosis and appropriate management can relieve the patient's agony and may be helpful in preserving the vision (Figure-1a, b \& c).

Most common associated presentation in our study is pain whether ocular pain or headache comparable to another study ${ }^{13}$ however, it was not a statistically significant in differentiating the etiology of proptosis $(p>0.05)$.
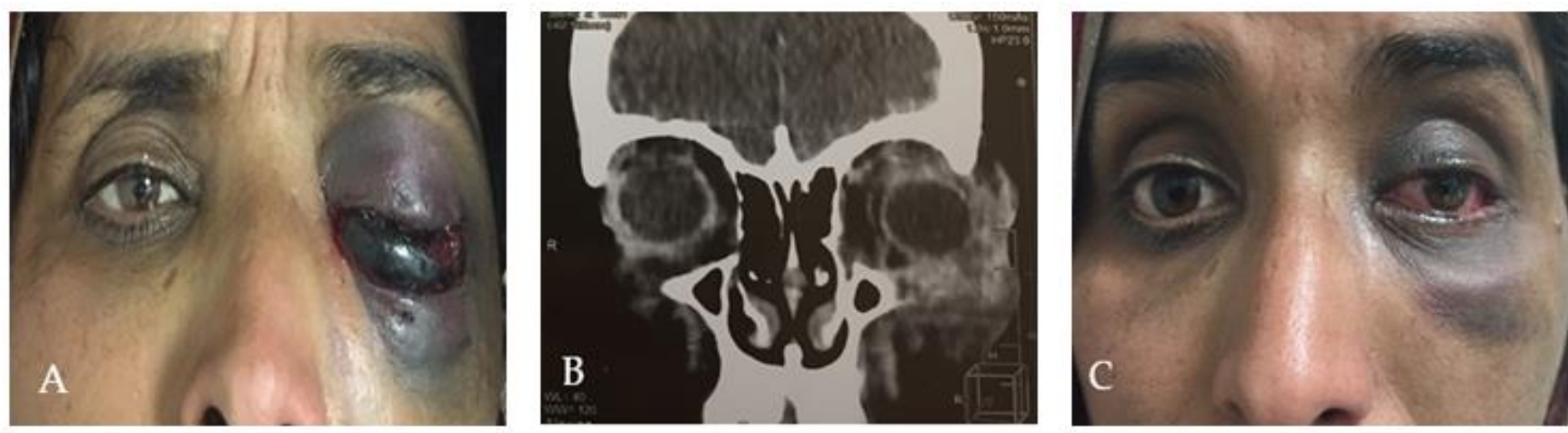

Figure-1(a-c): A case of acute orbit, a): 47-years old house wife, initially treated as preseptal cellulitis left eye. History revealed cardiac surgery a month back followed by IV anticoagulants and now raised INR, b): On CT Orbits, it turned out as orbital hemorrhage left eye. An urgent canthotomy and cantholysis relieved the patient's agony, c): 2 weeks later.

Regarding the cause of proptosis, 12 patients $(36.36 \%)$ had benign etiology, most common being pleomorphic adenoma in 4 cases (33.33\%). Malignant tumours were found in 7 patients $(21.11 \%)$ with most
As far as the investigations are concerned, both laboratory and radiological modalities are helpful. Doppler ultrasound is useful in differentiating vascular tumors however, tissue biopsy is diagnostic and 
must be performed in all doubtful cases. ${ }^{14}$ Thyroid function tests are necessary in the evaluation of any case with unilateral or bilateral proptosis, ${ }^{15,16}$ especially in absence of other signs and symptoms pointing towards a specific etiology. ${ }^{17}$ In our study, there was only one case of thyroid eye disease that presented with unilateral proptosis and raised serum thyroid hormones level. It was managed by antithyroid drugs as well as oral steroids to control the acute inflammation in collaboration with medical specialist. After the medical treatment, there was total recovery from the inflammatory stage and mild reduction in proptosis.

Pertinent radiological tests include CT scan, MRI and ultrasound. CT scan carries the risk of radiation exposure however MRI is safe in this context, is preferred for orbital apex lesions, optic nerve disease, and is helpful in assessing intracranial extension of a lesion. ${ }^{18}$ In case of orbital disease, both the coronal and axial views are helpful in assessing the extent and dimensions of the lesion. These radiological modalities also help in differentiating between an extraconal and intraconal lesion. Generally, an intraconal mass cause axial while extraconal mass causes non axial proptosis or dystopia. In this study, the percentage of patients with axial and non-axial proptosis was $48.5 \%$ and $51.5 \%$ respectively however another study reflects the converse. ${ }^{13}$

Majority of patients in this study had a spaceoccupying lesion in orbit that was causing the protrusion. Being either benign or malignant majority was managed surgically followed by chemo/radiotherapy in a few. Common benign cause of proptosis is pleomorphic adenoma while the most common malignant cause found was lymphoma in comparison to other studies in which they concluded the inflammation being the most common cause. ${ }^{13}$ Most of other cases with inflammatory or other miscellaneous conditions were managed medically depending upon the specific etiology. Majority of patients in our study were completely treated and there was only one death during the study period. As mentioned in literature, tissue biopsy is co-nsidered a gold standard in diagnosis, ${ }^{17}$ we also found it to be significantly superior to radio imaging.

\section{CONCLUSION}

Unilateral proptosis is a diagnostic challenge. Pertinent history taking and detail examination is the key, but associated signs or symptoms not always point towards correct diagnosis. Tissue biopsy may be conclusive especially where diagnosis by radio imaging is doubtful.

\section{Conflict of Interest: None.}

\section{Authors' Contribution}

UUY: Direct/Intellectual, MAY: Direct/Intellecutual, SAHN: Data collection, MS: Data analysis, AH: Data analysis, MA: Data analysis and proof reading.

\section{REFERENCES}

1. Umerani MS, Burhan H, Sharif S, ul Islam T, Ghaziani MH. Orbital Meningoencephalocele and Pulsatile Proptosis: A Rare Entity. Cureus 2018; 10(1): 1-5.

2. Epstein O, Perkin GD, Cookson J, de Bono D. Clinical exami-nation ( $3^{\text {rd }}$ ed). Edinburgh; New York: Mosby. 2003, [Internet] Available at: https://www.worldcat.org/title/clinical-examination/oclc/ 1165402911 (Assessed: Jan 1, 2016).

3. Park NR, Moon JH, Lee JK. Hertel exophthalmometer versus computed tomography scan in proptosis estimation in thyroidassociated orbitopathy. Clin Ophthalmol (Auckland, NZ) 2019; 13(2): 1461-65.

4. Melki I, Nassej O, Maroua E. Radiological aspects of proptosis 2017: European Congress of Radiology 2017, [Internet] Available from: https://epos.myesr.org/poster/esr/ecr2017/C-0990 (Assessed: Jan 1, 2016)

5. Aiyekomogbon JO, Chom ND, Hamidu AU, Rafindadi A, Ibinaiye PO. Normative measurements of the ocular globe position in relation to interzygomatic line, using magnetic resonance imaging among adults in Zaria, Nigeria. West Afr J Radiol 2016; 23(2): 118-123.

6. Turnbull A, Trikha S, Whaley C, Gibson D, Kashef E. Acquired unilateral proptosis-an overview of aetiology and radiological considerations. RAD Mag 2016; 42(488): 15-17.

7. Frueh WT, Frueh BR. Errors of single-mirror or prism Hertel exophthalmometers and recommendations for minimizing the errors. Ophthal Plast Reconstr Surg 2007; 23(3): 197-201.

8. Schmidt P, Kempin R, Langner S, Beule A, Kindler S, Koppe T, et al. Association of anthropometric markers with globe position: A population-based MRI study. PloS One 2019; 14(2): 1-6.

9. O'Donnell NP, Virdi M, Kemp EG. Hertel exophthalmometry: the most appropriate measuring technique. Br J Ophthalmol 1999; 83(9): 1096B.

10. Delmas J, Loustau JM, Martin S, Bourmault L, Adenis JP, Robert PY. Comparative study of 3 exophthalmometers and computed tomographic biometry. Eur J Ophthalmol 2018; 28(2): 144-49.

11. Costan V, Costan R, Bogdanici C, MoisiiL, Popescu E, Vulpoi C, et al. Surgery for Graves' Ophthalmopathy: when and what for. The experience of Iasi. Acta Endocrinol 2012; 8(4): 575586.

12. Osguthorpe JD, Hochman M. Unilateral Proptosis. In: Gates GA. eds. Current therapyin otolaryngology-Head and Neck Surgery. Baltimre: Mosby 1998: 1(1): 391-395.

13. Dsouza S, Kandula P, Kamath G, Kamath M. Clinical profile of unilateral proptosis in a trtiary care centre. J Ophthalmol 2017; 2017(2): 8546458.

14. Qazi ZU, Latif S, Awan SM. Orbital involvement in sinonasal diseases. J Ayub Med Coll Abbottabad 2016; 28(4): 687-693.

15. Héran F, Bergès O, Blustajn J, Boucenna M, Charbonneau F. Tumor pathology of the orbit. Diagn Interv Imag 2014; 95(10): 933-44.

16. Costan VV, Preda C, Bogdanici C, Trandafir D, Costan R, Vicol C, et al. Surgical treatment in graves ophthalmopathy - case report. Acta Endocrinol 2008; 4(3): 345-352.

17. Munoz J, Kurzrock R. Unilateral proptosis. J Am Med Assoc 2013; 309(6): 605-606.

18. Karcioglu ZA. Orbital tumors- diagnosis and treatment. Springer, 2005, [Internet] Available from: https://www.springer.com/gp/ book/9781493915095 (Assessed: Jan 1, 2016). 